\title{
DIAGNOSTICS OF CONFLICTS WITHIN THE BUSINESS SOCIAL RESPONSIBILITY FORMING SYSTEM
}

\section{- Iryna Khoma, Liudmyla Moroz, Pavlo Horyslavets}

\begin{abstract}
This article considers the approaches to early diagnostics of business conflicts within the system of business social responsibility forming during the process of thorough decision-making, and under conditions of uncertainty regarding the flow of business activity for the purposes of 'problematic' companies' crisis recovery and competitiveness restoration. Itshows that a quality business activity should presuppose elements of early identification of signs of business conflicts with the search for possible instruments to neutralize them. This is currently an important condition for business development. The study was also aimed at aspects of the impact of business conflicts on the diagnosed level of economic protectability of 'problematic' economic entities and their crisis recovery as full-pledged participants of business activity social responsibility system development - a constituent of the state economic development. We drew the methodology for detection of conflict situations based on signs of business conflicts identification, and suggested an innovational approach to modeling of the business uncertainty level with timely settlement of business conflicts. We carried out an analysis of major subsystems of crisis company management during the emergence of conflict situations that effectively influence the restoration of competitiveness and the system of forming social responsibility in today's business world.
\end{abstract}

Keywords: diagnostics, business conflicts, competitiveness, level of economic protectability of 'problematic' company, crisis management, social responsibility of business JEL Classification: A14, C13, D74, D81, G33, M21, M41.

Received: February, 2018

1st Revision: August, 2018

Accepted: August, 2018

\section{INTRODUCTION}

The purpose of almost any business is generating income, without obstacles, and further increasing it, avoiding unnecessary and unexpected costs. Costs may be either a result or a prolonged consequence of various business conflicts, which may in the future destabilize and totally ruin the integrity and basic strategy as well as economic protectability of the business activity itself. Therefore, a scientific problem of diagnostics arises, which is the detection of business conflicts 
at their early stages and the future forecast of the probability of their recurrence in the business social responsibility forming system with the assurance of persistently high levels of economic protectability of economic entities of strategical importance for the state. This study was aimed at early diagnostics of the signs of business conflicts, their impact on competitiveness and the level of a business activity's economic protectability in the business social responsibility forming system. This scientific direction is important for decreasing the number of 'problematic' companies, especially under conditions of financial and economic uncertainty.

Besides the primary objective, this study also provides the following:

1) generalization of reasons for the emergence of developed business conflicts in a business activity; 2) defining the basic factors of business conflicts management and characterizing them through mathematical descriptions; 3) forming the methodology for predicting the interrelation between the business conflicts flow and the elements of assessment of the company's economic protectability state; 4) forming an interrelation between the business conflicts forecast and the system of business social responsibility; 5) early identification of primary signs of business conflicts in a business environment; 6) analysis of companies that are 'problematic' in terms of worsening their social and economic situations; 7) introduction of a methodology for the management of a 'problematic' company through the establishment of a quantity-based interrelation between the diagnosed level of economic protectability and degree of 'problematic character' for the purpose of the adjustment of basic management functions involving the subsystems of crisis management, to improve the general business development strategy; 8) the applied usage of economical and mathematical methods to reveal this problem.

\section{THEORETICAL BACKGROUND}

A review and analysis of recent studies and publications has shown that Ukrainian business activity increases the scale of its participation in solving various social issues, the list of which begins with potential directions for activity with business social responsibility.

Business social responsibility, for the likes of Adelkin (2005), Saienko (2002), Starodubska (2005) and others, should be interpreted as a property that enables the correct managing of commercial activities of companies and other market operators to create a positive societal effect. Therefore, business social responsibility is the financial and economic responsibility of a production structure for the performance of quality multilateral business operations and the maintenance of a high level of profitability, earning capacity, cost efficiency and economic protectability via certain accepted tools and control measures.

Porter (2017) has proven that business makes the economy operate. However, the economy may have an adverse effect on the development of a business activity - that is, to broaden the options for its competitive strategy based on fairness and economic confidence. The problem of researching the detection of problematic areas in the activity of industrial companies, affected by crisis situations and, namely, different conflicts, including economic ones, was explored by both foreign and Ukrainian scientists such as Bielikov (2013), Bobryshev (2012), Kapitonenko (2009), Osovska (2003), Yurchenko (2007) and many others. They managed to explore the factors of conflict emergence and to analyze the nature of the occurrence with a spontaneous or 
typical incompatibility of interests of parties to business agreements. However they did not concentrate on studying the essence of business conflicts' influences and the effect of measuring the level of companies' economic protectability, namely 'problematic' ones, on the basis of quantity economic and mathematical methods, and for the nature of a business's social responsibility development in general.

With regard to the review of literary sources, it can be argued that the tasks of scientific issues require a further detailed study.

\subsection{The nature of business conflicts in a business activity}

Any conflict, and namely, in a business activity, having multifaceted generation nature and individual character of influencing the development of a specific economic entity, is based on inconsistent interests of business partners. These inconsistent interests may occur either immediately, or in certain time span from the start of conclusion of business agreements, and will be characterized by the partial or complete loss of certain level of interaction between these partners on the market, and, in particular, loss of economic confidence between them that in the future, in most cases, may lead to serious economic and social problems, violating the balance of established relations. Due to this, there occurs a problem of forming, adequate in the context of real environment, conceptual essence that would uncover the sense of not only generation and flow of business conflicts, but also the influence of conflict situations on the present state of company's economic protectability.

The conducted research allows generalizing the following primary grounds for emergence of most business conflicts in the business activity that destabilize the system of business social responsibility, and namely: 1) communication disorder in the business activity; 2) inability for preventing conflicts or their improper forecasting; 3) disruption of balance between the parties of business agreements in development of managerial solutions; 4) underestimation of business partners' properties; 5) late discovery of discrepancies between the actors of business relations establishment; 6) breach of agreements on various stages of business agreements conclusion or initial violation of business strategy; 7) purposeful infliction of economic damage to the other party of business contract, etc.

Besides, any economic conflict should be considered a formed conflict since the moment when conditions of a business agreement are violated or purposefully ignored. It means that 'conflict is a situation when participants of relations, united by the same object, realize incompatibility of their interests regarding it and act with account of such realization' (Kapitonenko, 2009, p. 10). The scheme of a recommended forming of interrelation between the business conflicts flow and assessment of the state and, namely, the level of the company's economic protectability, is shown in Fig. 1. 


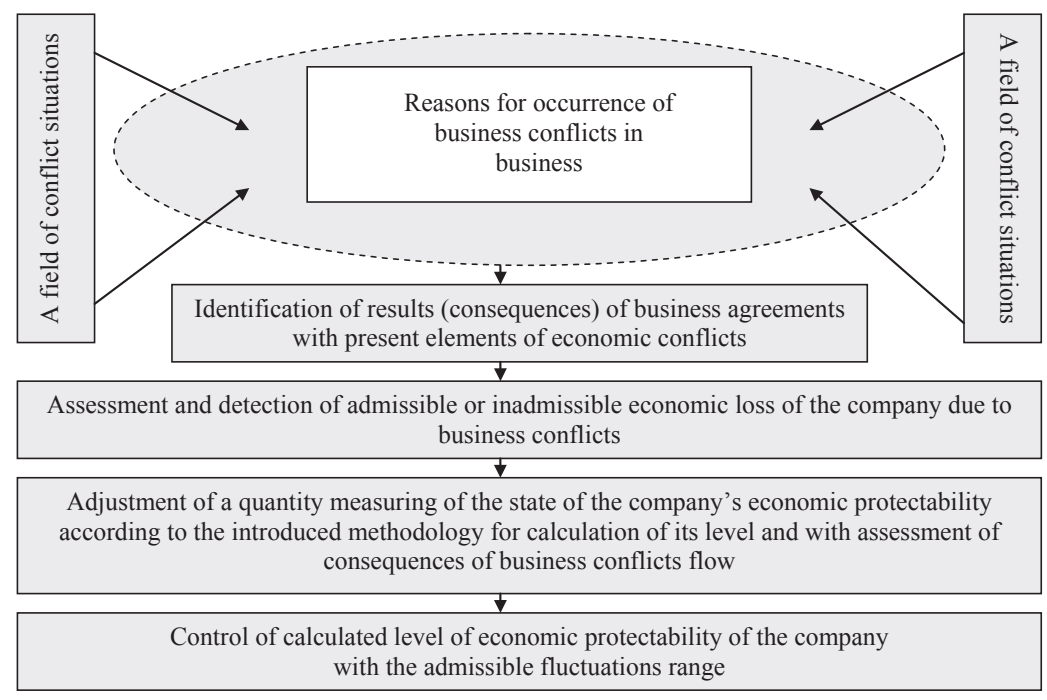

Fig. 1 - Development of interconnection between the business conflicts flow and the elements of assessment of the state of the company's economic protectability. Source: authors' own

All the reasons for emergence of business conflicts in business are individual, though the field of conflict situations in business environment may be forecasted in advance on the basis of previous research of consequences of business agreements.

\subsection{The influence of business conflicts on destabilization of the business social responsibility system}

The social responsibility of entrepreneurship is necessary for development of business. There are few socially responsible enterprises and companies at the moment. Therefore, their experience in this sphere is quite valuable. Any production structure cannot be successful in business and social responsibility, if around or inside of it, there are various conflict situations, destabilizing this property of the company and simultaneously ruining its integrated economic protectability, developed. Today's state of business activity depends on the right approach to assessment of conflict situations that might, from time to time, appear in internal and external environment of production and economic structures during their development of business commercial cooperation.

Business social responsibility is not directly linked to the uncertainty of entrepreneurial activity. However, business conflicts and their consequences border on uncertainty that emerges in situations with a range of unknown factors that are difficult to be foreseen in advance, namely in the course of conflict situations themselves.

Though, in prevention of business conflicts and their timely prognosis, the level of social responsibility of business activity $\left(R_{\text {social responsibility of business activity }}\right)$ increases as these factors and the level of uncertainty $\left(R_{\text {uncertainty }}\right)$ have inverse correlation as follows: 


$$
R_{\text {social responsibility of business activity }}=1 / R_{\text {uncertainty }}
$$

Uncertainty is deficiency or inaccuracy of information under conditions of implementation of projects (programs) elaborated by the company, including those related to current expenses and final, not forecasted, results. In most cases, the account of uncertainty is performed in three ways: by checking stability of an elaborated project (program); adjustment of project indicators and economic standards; a formalized description of uncertainty (Donets, 2006, p. 102). In our case, the level of business uncertainty may depend on basically two major factors — chaotic dynamics of the level of business project stability $\left( \pm \Delta R_{\text {stability }}\right)$ and a number of business conflicts $\left(B_{c}\right)$ with a prolonged undefined period for their settlement. Therefore, the functional dependence of the level of business uncertainty on the above-mentioned factors may be expressed as:

$$
\mathrm{R}_{\text {uncertainty }}=f\left( \pm \Delta \mathrm{R}_{\text {stability }} ; B_{c}\right)
$$

When having commercial negotiations or concluding of business agreements, the conflict situation along with an incident or a reason for incident becomes a conflict area. A conflict area is not always efficiently included in the management process as it may presuppose a considerable number of vectors for development of business conflicts in a business activity (Bielikov, 2013).

\section{RESEARCH OBJECTIVE AND METHODOLOGY}

With a growing topicality of the issue of the business social responsibility and increase of its social culture, the primary task is development of methodology for early diagnostics to detect business conflicts and introduce the forecasting approach towards a precise definition of probability of their occurrence that provides for the foreseen level of economic protectability for both individual company, and all its partners - business structures, signing into contracts or competing on the market.

The research methodology requires complex practice for detection of the first signs of business conflicts, first of all, regarding the 'problematic' companies that have lost their financial solvency for the present time and it is early diagnostics of negative consequences of conflict situations that is important to them. During the crisis, their level of economic protectability becomes considerably lower, but some, in contradiction to most problems, do strive to resume the state of their protection, having applied various anti-crisis measures and become full-pledged participants in the business social responsibility forming and general development of the state's economy.

At present, the entrepreneurship does not have an elaborated mechanism for early diagnostics and neutralization of business conflicts in the business social responsibility forming system, and therefore, this research is topical. All the data on business conflicts are mostly confidential, and the statistical data on the consequences of conflict situations are quite unrevealed and restricted by the position of real facts, and therefore, the primary source may only be the basic form of financial statements of the companies, providing general information on the dynamics of financial and economic state of the economic entity, including recessive dynamics due to action of separate business conflicts. The data are taken from expert surveys and statistics of actual conflict situations in the business activity with the elements of imitating modeling with the applied use of a broad range of economic and mathematical methods. Using own researches, it is 
recommended to prefer diagnostics of the company's economic protectability according to the method of structural and functional diagnostics of its level through a range of indicating factors, noting all, even the minor deviations from the standard values.

The research methodology also includes defining the position for introduction of subsystems of crisis management within the companies, no 'problematic' enterprise can go without, if the business activity has lost its positions, in particular, due to business conflicts.

\subsection{The diagnostics of signs of business conflicts in forming business social responsibility}

A timely detection and further prevention of business conflicts requires a complete differentiation of their signs in advance. The main diagnosed signs of business conflicts on the companies may include the following:

1) identification of a higher value of the company's economic loss, than the one planned, due to conflict situations:

$$
\Delta L_{E}=L_{E}^{1}-L_{E}^{0},
$$

where $L_{E}^{0}$ is an economic loss of the company for the reference period; $L_{E}$ is an economic loss of the company for the reporting period; $\Delta L_{E}$ is an absolute value of change in economic loss of the company for the reporting and reference period with the division according to levels of its 'problematic character', and namely: $L_{E}^{1} ; L_{E}^{2} ; L_{E}^{3} ; L_{E}^{4}$, where $\Delta L_{E}^{1} \rightarrow\left(-v_{1} ; 0\right]$ is a 0 -level of the company's 'problematic character'; $\Delta L^{2}{ }_{E} \rightarrow\left(0 ; \mathrm{v}_{2}\right]$ is a 1-level of the company's 'problematic character'; $\Delta L_{E}^{3} \rightarrow\left[\mathrm{v}_{2} ; \mathrm{v}_{3}\right]$ is a 2-level of the company's 'problematic character'; $\Delta L_{E}^{4} \rightarrow\left(\mathrm{v}_{3} ; \mathrm{v}_{4}\right]$ is a 3-level of the company's problematic character' that fixes the presence of exceeded economic loss due to a business conflict where $\mathrm{v}_{1} ; \mathrm{v}_{2} ; \mathrm{v}_{3} ; \mathrm{v}_{4}$ are limit values of a range of admissible and inadmissible economic loss of the company.

2) identification of drop in the value of net cash flow $\left(N_{C F}\right)$ :

$$
N_{C F}=P+A_{d}-I \text {, }
$$

where $P$ are profits from production activity; $A_{d}$ are amortization deductions; $I$ are expenses on investment in the capital production;

3) identification of a recessive tendency for the value of net profit (NP):

$$
N P=\left[V_{P} \times P_{P}\left(E^{C}+E^{v}+V_{P}\right)+P_{L}\right] \times\left(1-\left(i_{P} / 100 \%\right)\right),
$$

where $V_{P}$ is a volume of production in natural units; $P_{P}$ is a product price; $E^{C}$ are conditionally constant expenses on product manufacture; $E^{p}$ are conditionally variable expenses per product unit; $P_{L}$ is a liquidation profit from the product sales; $i_{P}$ is an active taxation rate for the company profit.

4) identification of zero effectiveness of the business agreements concluded:

$$
B^{u_{1}} I B^{u_{2}}=\varnothing \text {, }
$$

where $B^{u}{ }_{1}, B_{2}{ }_{2}$ are business agreements; $I$ is crossing (consistency) of business agreements on joint conditions; $\varnothing$ is zero efficiency of bilateral business agreements. 
5) failure to achieve agreement and equality of parties to business agreement:

$$
B^{u_{1}} I B^{u_{2}} \neq B^{u}{ }_{2} I B^{u}{ }_{1},
$$

where $\neq$ is a sign of disagreement (inequality) in achievement of interests of parties to the business agreements.

6) non-compliance with the principle of generalization of business relations or inability to differentiate commercial risk as a result of conclusion of business agreements:

$$
f\left(B^{u}\right) \neq f\left[\int_{\mathrm{D}} \chi_{\mathrm{B}}{ }^{\mathrm{u}}(\mathrm{d}) / \mathrm{d}\right],
$$

where $f\left(B^{\prime \prime}\right)$ is a function of a planned, but not performed generalization of business relations of partners in conclusion of business agreements in case of inability to place business agreement into characteristic series of a type: $B^{n} \neq\left(\chi_{1} / d_{1}\right)+\left(\chi_{2} / d_{2}\right)+\ldots+\left(\chi_{n} / d_{n}\right) ; \chi_{1}, \chi_{2}, \ldots, \chi_{n}$ is a characteristic informational function on a state of riskiness or active capacity of business agreement in a company; $d_{1}, d_{2}, \ldots, d_{n}$ is a discontinuous carrier that fixes conclusion of active business agreements and sequence of their consideration, $d_{i} \in D^{*}$ (Konysheva \& Nazarov, 2011).

7) violation of agreed provisions in the course of business agreements (inability to apply multicriterial optimization of interests of the parties of business agreements):

$$
F\left(x^{*}\right) \neq \max _{x \in Z_{x}} \min _{i} z_{i}(x) ; F\left(x^{*}\right) \neq \min _{x \in Z_{x}} \max _{i} z_{i}(x),
$$

where $F\left(x^{*}\right)$ is a planned for performance criterion or a principle of uniform optimization of managerial solutions regarding settlement of business conflicts, though not performed; $z_{(}(x)$ are business decisions that in settlement of conflict situations replace financial and economic results of business activity; $i=\overline{1, n} ; \chi$ is a characteristic variable that becomes variable $\chi^{*}$ in the optimization process; $Z_{x}$ is a multitude of 'compromises' in settlement of business conflicts.

8) identification of a low actual value of sales of ready products if compared to the planned value due to conflict of interests in marketing planning:

$$
z=\left(\left(\tau_{\max }+4 \times \tau_{\text {aver }}+\tau_{\text {min }}\right) / 6\right) \pm 2 \times\left(\left(\tau_{\max }-\tau_{\text {min }}\right) / 6\right),
$$

where $z$ is a planned value of sales, pcs; $\tau_{\text {max }}, z_{\text {min }}$ are maximum and minimum expert assessments of sales, pcs; $z_{\text {aver }}$ is an average expert assessment of sales, pcs; ( $\left.\tau_{\max }-z_{\min }\right) / 6$ is an admissible value of standard deviation.

9) non-achievement of standard value regarding the relative rate of change in current financial investments $\left(k_{\triangle F I}\right)$ due to business conflicts with investors:

$$
k_{\Delta F I}=C F I^{1} / C F I^{0}<1
$$

10) non-achievement of standard value regarding the rate of change in absolute liquidity ratio $\left(\mathrm{k}_{\Delta a}^{\Delta F I}\right)$ with participation of current financial investment due to business conflicts and rapid deterioration of financial and economic state on the company:

$$
\left(k_{\Delta a}^{\Delta F I}\right)=k_{a}^{1} / k_{a}^{0}<1,
$$

where $k_{a}^{0}=\left(M^{0}+C F I^{0}\right) / C^{0} ;=k_{a}^{1}=\left(M^{1}+C F I^{1}\right) / C^{1}$, where $C F I^{0}, C F I^{1}$ are are current financial investments for the reference and reporting periods; $k_{a}^{0} ; k_{a}^{1}$ is an absolute liquidity ratio for the reference and reporting periods; $M F^{0}, M F^{1}$ are monetary funds and their equiva- 
lents present at the company in the reference and reporting periods; $\mathrm{CFI}^{0}, \mathrm{CFI}^{1}$ are the current financial investments in the reference and reporting periods; $\mathrm{CO}^{\circ} ; \mathrm{CO}^{1}$ are current obligations for the reference and reporting periods.

11) non-achievement, by the company, of standard value of the inventive activity level $\left(l_{i a}\right)$ that does not allow making weighted managerial decisions regarding implementation of scientific research results:

$$
l_{i a}=k_{0} / Z+k_{a b} / Z+v^{a c t} / v<2,
$$

where $k_{0}$ is a number of company's employees with a necessary level of education; $Z$ is a total number of employees; $k_{a b}$ is a number of employees with the corresponding academic background; $v^{\text {act }}$ is an actual level of psychological climate in a group of inventive activity; $v$ is a maximum level of psychological climate in a group of inventive activity, in points.

12) non-achievement of a standard value of indicator of fundamental and applied researches $\left(K_{f a r}\right)$ in arrangement of a manufacturing process:

$$
K_{\text {far }}=\left(K^{t} / K^{t-1}\right)<1 \text {, }
$$

where $K^{t}, K^{t-1}$ is a number of fundamental and applied researches in arrangement of of manufacturing process for the reporting and reference periods.

13) incorrectness in definition of objective value of expenses due to subjective factor (their increase or decrease) under conditions of company liquidation and calculation of liquidation cost $\left(C_{I}\right): C_{L}=A_{L}-O-E_{L}$, where $A_{L}$ is a liquidation cost of assets; $O$ are obligations; $E_{L}$ are expenses, related to liquidation cost of a company or its assets (Moroz \& Khoma, 2017), (Khoma, 2017).

\subsection{The actions of subsystems of crisis management under business conflict conditions}

Today's activity of companies, even under conditions of financial recovery is not immune to business conflicts, consequences of which destabilize not only current financial and economic state and state of economic protectability, but may also distort or restrain, for the indefinite period, the attainment of all results of the planned implementation of anti-crisis procedures that must be applied towards specific economic agent for the purpose of its 'rehabilitation'.

A significant number of scientists have researched crisis company management in the context of crisis issues themselves. These are the following national scientists: Vasilenko (2001), Rayevnyeva (2012), Tereschenko (2004), Chernyavskiy (2005), and the following foreign scientists: Boin \& Lagadec (2000), Pearson \& Clair ( 1998), Lerbinger (2012), Mitroff (1991), Pauchant, Mitroff \& Lagadec (1991) and many others. In most cases, they were acting purposely in a local context, either developing general notions and crisis typologies and their diagnostics, or forming a strategic plan of crisis company management with account of assessment of internal state of 'problematic' economic agents, sale markets, investment projects, or optimization of production relations and financial resources without specifically considering particular aspects of effects from the generated business conflicts and their consequences for efficiency of crisis management system.

As we know, the notions 'crisis management' and 'financial recovery' are closely correlated with 
one another. Crisis management is a unity of forms and methods for implementation of anticrisis procedures that are applied to the specific company for the purposes of its rehabilitation (Bazarov et al.1996, p. 33). Financial recovery is a system of economic and organizational events aimed at rehabilitation of debtor company's financial state, though this provision does not apply to financial recovery of a debtor company in case of institution of bankruptcy proceedings (Chernyavskiy, 2005, p. 82).

More dangerous character is peculiar to those conflicts that may occur in the process of elaboration and introduction to the action of separate subsystems of crisis company management, blocking their positive ultimate result - rather rapid neutralization of the crisis state on the economic entity. Then the efficiency of this subsystem becomes doubtful and does not allow preserving production process and competitiveness in any situation development.

The full-pledged mechanism for blocking negative consequences of business conflicts in a business social responsibility forming system with company's crisis management should contain the following elements:

- identification of influence of negative consequences of business conflicts on the basis of its subsystem that are equally efficient under conditions of financial recovery of economic entity (this identification process will be based on a differentiated list of negative features of conflict situations according to the detected sign with economical and mathematical description and identified influence on specific subsystems of the company's crisis management;

- forming the list of events that block spreading negative consequences of business conflicts, results of which will restore and activate implementation of anti-crisis procedures in the company.

The full-pledged mechanism of crisis management consists of the following subsystems:

1) subsystems for diagnostics of financial state and assessment of business development prospects (or bankruptcy diagnostics and monetary flows planning diagnostics); 2) marketing subsystems; 3) subsystems of anti-crisis investment policy; 4) HR management subsystems; 5) production management subsystems; 6) company liquidation arrangement subsystems (Bazarov et al. 1996). Each of these subsystems is responsible for expected financial and economic results that require immediate change during the extreme deterioration of the company's economic situation, and namely in the conditions of business conflicts influence. A long-term identification of higher value of the company's economic loss than the one planned, identification of drop in the value of net cash flow and identification of recessive tendency of the net profit value must fall within the responsibility of subsystem for diagnostics of financial state and assessment of company's business development prospects. The identification of low actual value of sales, if compared to the planned one, must fall within the responsibility of marketing subsystem. Violation of control regarding relative rate of change in current financial investment and control of relative rate of change in absolute liquidity ratio with participation of current financial investments must fall within responsibility of subsystem of anti-crisis investment policy. Violation of control of the level of an inventive activity that allows making weighted managerial decisions as to implementation of scientific research must fall within the responsibility of HR management subsystem and violation of control over the value of fundamental and applied researches in arrangement of manufacturing process must fall within the responsibility of production management subsystem. 
In case of the erroneous definition of costs under conditions of the company's liquidation and calculation of the liquidation costs, the anti-crisis measures are performed by the subsystem of the company's liquidation arrangement.

\section{RESULTS AND DISCUSSION}

In order not to allow occurrence of complete crisis state, it is recommended to combine tactics of managing 'problematic' companies with information of the company, having been already diagnosed for the date, as to their economic protectability, and, namely, due to action of business conflicts. Let's assume that a certain economic entity, within a reporting calendar year, concludes a range of business agreements with constant number of partners, and they also enter into economic relations between themselves, and besides, they know, in advance, the probability for emergence of some conflict situations (see Tab. 1).

Tab. 1 - Imitation matrix of probability for occurrence of conflicts when concluding business agreements. Source: (Khoma, 2014)

\begin{tabular}{|l|l|l|l|l|l|l|}
\hline & $B_{p}^{1}$ & $B_{p}^{2}$ & $B_{p}^{3}$ & $B_{p}^{4}$ & $B_{p}^{5}$ & $B_{p}^{6}$ \\
\hline$B_{p}^{1}$ & - & 0.2 & 0.1 & - & - & 0.3 \\
\hline$B_{p}^{2}$ & 0.2 & - & 0.5 & 0.3 & 0.4 & 0.5 \\
\hline$B_{p}^{3}$ & 0.1 & 0.5 & - & 0.7 & 0.3 & 0.3 \\
\hline$B_{p}^{4}$ & 0.1 & 0.3 & 0.7 & - & 0.6 & 0.5 \\
\hline$B_{p}^{5}$ & - & 0.4 & 0.3 & 0.6 & - & 0.2 \\
\hline$B_{p}^{6}$ & 0.3 & 0.5 & 0.3 & 0.5 & - & - \\
\hline
\end{tabular}

As we know, annual business agreements $B^{i}{ }$ with probability of occurrence of economic conflicts $P_{i}$, where $i$ is their sequential number, were concluded on the economic entity throughout the entire calendar year, though the exact probability of their occurrence with possibility to measure the average value was known only in the first three months.

$$
\begin{array}{rlrl}
\text { Month 1. } B^{1}{ }_{u} & =B_{p}^{1} Y B_{p}^{3} \rightarrow P_{1}=0.1 ; & & B^{3}{ }_{u}=B_{p}^{4} Y B_{p}^{5} \rightarrow P_{3}=0.6 ; \\
B^{2}{ }_{u}=B_{p}^{2} Y B_{p}{ }_{p} \rightarrow P_{2} & =0.5 ; & B^{4}{ }_{u}=B_{p}{ }_{p} Y B_{p}{ }_{p} \rightarrow P_{4}=0.3 .
\end{array}
$$

Average probability of business conflicts occurrence: $\bar{P}=0.375$

$$
\begin{array}{rlrl}
\text { Month 2. } B^{1}{ } & =B_{p}^{3} Y B_{p}^{5} \rightarrow P_{1}=0.3 ; & & B^{4}{ }=B_{p}^{1} Y B_{p}^{2} \rightarrow P_{4}=0.2 ; \\
B^{2}{ } & =B_{p}^{6} Y B_{p}^{4} \rightarrow P_{2}=0.5 ; & B^{5}{ }_{u}=B_{p}^{3} Y B_{p}{ }_{p} \rightarrow P_{5}=0.7 . \\
B^{3}{ }_{u} & =B_{p}^{2} Y B_{p}^{3} \rightarrow P_{3}=0.5 ; & &
\end{array}
$$

Average probability of business conflicts occurrence: $\bar{P}=0.44$

Month 3. $B^{1}{ }^{\prime}=B_{p}^{2} Y B_{p}^{5} \rightarrow P_{1}=0.4$;

$$
\begin{aligned}
& B^{2}=B_{p}^{3} Y B_{p}^{6} \rightarrow P_{2}=0.3 ; \\
& B^{3}=B_{p}^{4} Y B_{p}^{2} \rightarrow P_{3}=0.3 ;
\end{aligned}
$$

Average probability of business conflicts occurrence: $\bar{P}=0.333$ 
Then the annual probability of business conflicts occurrence will be: $\bar{P}_{y}=0.383$. This value corresponds to correction coefficient $B$.

In this situation, the integrated level of the company's economic protectability $\left(R_{E P}\right)$, influenced by the levels of innovational, financial and credit and investment protection (components of protectability), as well as value of additional destabilizing influence $\left(\varepsilon_{i}\right)$ that will appear if on the company there are proven and investigated economic crimes due to illegal actions, and correction coefficient ( $($ ) for specification of quantitative measuring of the level of economic protectability within all its components that will equal to the value of annual average probability for emergence of business conflicts with certain negative consequences, may be shown by the following dependence:

$$
R_{E P}=\sqrt[n]{\prod_{i=1}^{n}\left(L_{r}^{V}-\sum_{j=1}^{z} \frac{\Delta_{j}^{i} \mid}{N_{j}^{i}}-\varepsilon_{i}\right)}-\beta \pm \Delta,
$$

where $L_{r}{ }_{r}$ is a localized $r$ - dimensional scale for measuring levels of components and general level of economic protectability ( $\left.L_{r}{ }_{r}=10\right) ;\left|\Delta_{j}^{i}\right|$ are absolute distortions, according to the module of calculation values of indicating factors from the standard values; $N_{j}{ }_{j}$ are standard values of indicating factors; $n$ is a number of diagnosed components of protectability $(n=3)$; $z$ is an optimal number of selected indicating factors; $\pm \Delta$ is admissible calculation error that does not change the state of protectability within fixation of the corresponding low, medium or high level (Khoma, 2015;Alieksieiev \& Khoma, 2017).

The information on a diagnosed level of economic protectability of the 'problematic' companies under the influences of business conflicts allows, within a limited time, defining objective degree of 'problematic character' of this economic entity in the system of forming business social responsibility.

In the real-time conditions, during the process of forming the business social responsibility system, one can emerge from a crisis state if offered an efficient method for defining a degree of 'problematic character' of an enterprise based on the diagnosed level of economic protectability, adjusted for the influence of business conflicts. It is recommended to diagnose economic protectability of the company by the method of structural and functional diagnostics through a range of indicating factors, fixing their tiniest deviations from the standard values. There may also be used a systemic and complex express diagnostics, taking into account the transversality property with the criteria defined in advance (Khoma, 2012).

According to these diagnostic methods, the range of economic protectability level may vary correspondingly in the limits $[0 ; 10]$ or $[0 ; 24]$. The admissible lower limit of economic protectability level will never be equal to zero.

In order to find the lower admissible level of company's economic protectability and specify the upper level under conditions of active business conflicts, we will use the Wald criterion regarding adoption of optimal decisions max-min and max-max (Pryimak, 2008, p. 148). 
Let's model the activity of conventional enterprise for the period of three years of its functioning (we will take as a basis a range of company's economic protectability level according to the method of structural and functional diagnostics) (see Tab. 2).

Tab. 2 - The results of lower and upper limits of the admissible level of economic protectability of the modeled company under conditions of active business conflicts and uncertainty according to the Wald criterion. Source: authors' own on the basis of imitation modeling results

\begin{tabular}{|l|l|l|l|l|l|}
\hline \multirow{2}{*}{$\begin{array}{l}\text { Year } / \\
\text { Month }\end{array}$} & \multicolumn{3}{|c|}{$\begin{array}{c}\text { The diagnosed level of economic protectabil- } \\
\text { ity }\left(R_{E P}\right)\end{array}$} & \multicolumn{2}{c|}{ Wald criterion } \\
\cline { 2 - 7 } & 1 -st year & 2 -nd year & 3 -rd year & max - min & max - max \\
\hline January & 0 & 2 & 9 & 0 & 9 \\
\hline February & 0 & 2 & 8 & 0 & 8 \\
\hline March & 2 & 3 & 5 & 2 & 5 \\
\hline April & 1 & 3 & 4 & 1 & 4 \\
\hline May & 3 & 9 & 6 & 3 & 9 \\
\hline June & 0 & 6 & 10 & 0 & 10 \\
\hline July & 0 & 7 & 3 & 0 & 7 \\
\hline August & 4 & 4 & 6 & 4 & 6 \\
\hline September & 6 & 9 & 7 & 6 & 9 \\
\hline October & 5 & 8 & 6 & 5 & 8 \\
\hline November & 7 & 9 & 5 & 5 & 9 \\
\hline December & 2 & 9 & 5 & 2 & 9 \\
\hline
\end{tabular}

According to the results of Tab. 2, the admissible level of economic protectability in the business structure will range within the limits $[6 ; 10]$ with an average value of 8 points.

Therefore, to specify upper value of the level of economic protectability it is recommended, in extreme conditions, to use $\alpha$ - Hurwitz criterion with the value of $\alpha=0,5$, which is taking an average value in a range of $0 \leq \alpha \leq 1$ between criterion max-min and max-max.

The interim calculations are performed according to the following formulas:

$$
\begin{aligned}
& \bar{R}_{E P}^{i}=\alpha \times \max R_{E P}^{i}+(1-\alpha) \times \min R_{E P}^{i} \\
& \bar{R}_{E P}=\max _{i=1,12}\left\{\bar{R}_{E P}^{i}\right\},
\end{aligned}
$$

where $i$ is a corresponding cluster, encompassing three years of the company's activity in the section of one calendar month $(i=\overline{1,12})$ with a selection of maximum value $\bar{R}_{E P}$, provided in Tab. 3 .

Tab. 3 - Values of the upper possible level of economic protectability of the modeled company conditions of active business conflicts and uncertainty according to Hurwitz $\alpha$-criterion. Source: authors' calculations 


\begin{tabular}{|c|c|c|c|c|c|c|c|c|c|}
\hline \multirow{2}{*}{$\begin{array}{l}\text { Year / } \\
\text { Month }\end{array}$} & \multicolumn{3}{|c|}{$\begin{array}{l}\text { Diagnosed level of } \\
\text { economic protectability } \\
\left(R_{E P}\right)\end{array}$} & \multirow[t]{2}{*}{$\alpha$} & \multirow{2}{*}{$\begin{array}{l}\max \\
\mathrm{R}_{E P}^{i}\end{array}$} & \multirow{2}{*}{$\begin{array}{l}\alpha \max \\
\mathrm{R}_{E P}^{i}\end{array}$} & \multirow{2}{*}{$\begin{array}{l}\min \\
\mathrm{R}_{E P}^{i}\end{array}$} & \multirow{2}{*}{$\begin{array}{l}(1-\alpha) \\
\min \\
\mathrm{R}_{E P}^{i}\end{array}$} & \multirow{2}{*}{$\overline{\mathrm{R}}_{E P}^{i}$} \\
\hline & $\begin{array}{l}1 \text {-st } \\
\text { year }\end{array}$ & $\begin{array}{l}\text { 2-nd } \\
\text { year }\end{array}$ & $\begin{array}{l}\text { 3-rd } \\
\text { year }\end{array}$ & & & & & & \\
\hline January & 0 & 2 & 9 & 0.5 & 9 & 4.5 & 0 & 0 & 4.5 \\
\hline February & 0 & 2 & 8 & 0.5 & 8 & 4 & 0 & 0 & 4 \\
\hline March & 2 & 3 & 5 & 0.5 & 5 & 2.5 & 2 & 1 & 3.5 \\
\hline April & 1 & 3 & 4 & 0.5 & 4 & 2 & 1 & 0.5 & 2.5 \\
\hline May & 3 & 9 & 6 & 0.5 & 9 & 4.5 & 3 & 1.5 & 6 \\
\hline June & 0 & 6 & 10 & 0.5 & 10 & 5 & 0 & 0 & 5 \\
\hline July & 0 & 7 & 3 & 0.5 & 7 & 3.5 & 0 & 0 & 3.5 \\
\hline August & 4 & 4 & 6 & 0.5 & 6 & 3 & 4 & 2 & 5 \\
\hline September & 6 & 10 & 7 & 0.5 & 10 & 5 & 6 & 3 & 8 \\
\hline October & 5 & 8 & 6 & 0.5 & 8 & 4 & 5 & 2.5 & 6.5 \\
\hline November & 7 & 9 & 5 & 0.5 & 9 & 4.5 & 5 & 2.5 & 7 \\
\hline December & 2 & 9 & 5 & 0.5 & 9 & 4.5 & 2 & 1 & 5.5 \\
\hline
\end{tabular}

As we can see from Tab. 3, under conditions of substantial risk, the admissible range of the level of economic protectability of a 'problematic' company even with a normal financial situation is significantly narrowed from the segment $[6 ; 10]$ to $[6 ; 8]$. Such distortions suggest a close interconnection between the company's level of economic protectability and degree of its 'problematic character' under the influence of certain conflict situations.

Using the Hurwitz $\alpha$-criterion is possible in the case of a rational substantiation of the level of market risk. On the condition of a rapid increase in the degree of 'problematic character' of the economic entity, it is recommended to establish an interrelation between the diagnosed level of the economic protectability (as adjusted for the adjustment coefficient $(\beta)$ ) with the selection of its maximum value for the row of last calendar years and build a matrix of losses as a difference between the maximum level of economic protectability $\left(R_{E P}\right)$ of the first, second, and third years of its activity and the level of economic protectability per the end of every month of the corresponding level. This is an important condition of the Savage criterion, which allows selecting the value of maximum losses of the company according to each matrix row so as to define, on their basis, the lowest value of losses among the maximum ones $\left(\max B_{i}\right)$ that would correspond to the degree of 'problematic character' of the economic entity for a certain period of functioning, when losses may prognostically increase as a consequence of active business conflicts.

Let us calculate the degree of 'problematic character' on the example of the modeled company, using the information of the diagnosed level of their economic protectability by the end of each calendar month for the period of three years and build a matrix of losses according to the Savage criterion. The interim and final calculation results are provided in Tab. 4. 
Tab. 4 - Determination of degree of the company's 'problematic character' based on the diagnosed level of economic protectability regarding active business conflicts and the Savage criterion. Source: authors' own

\begin{tabular}{|l|l|l|l|l|l|l|l|}
\hline \multirow{2}{*}{ Year / Month } & \multicolumn{2}{|c|}{$\begin{array}{c}\text { Diagnosed level of economic } \\
\text { protectability }\left(R_{E P}\right)\end{array}$} & \multicolumn{3}{c|}{ Matrix of losses } & \multirow{2}{*}{$\max B_{i}$} \\
\cline { 2 - 8 } & 1 -st year & 2 -nd year & 3 -rd year & 1-st year & 2-nd year & 3-rd year & \\
\hline January & 0 & 2 & 9 & 7 & 8 & 1 & 8 \\
\hline February & 0 & 2 & 8 & 7 & 8 & 2 & 8 \\
\hline March & 2 & 3 & 5 & 5 & 7 & 5 & 7 \\
\hline April & 1 & 3 & 4 & 6 & 7 & 6 & 7 \\
\hline May & 3 & 9 & 6 & 4 & 1 & 4 & 4 \\
\hline June & 0 & 6 & 10 & 7 & 4 & 0 & 7 \\
\hline July & 0 & 7 & 3 & 7 & 3 & 7 & 7 \\
\hline August & 4 & 4 & 6 & 3 & 6 & 4 & 6 \\
\hline September & 6 & 10 & 7 & 1 & 0 & 3 & 3 \\
\hline October & 5 & 8 & 6 & 2 & 2 & 4 & 4 \\
\hline November & 7 & 9 & 5 & 0 & 1 & 5 & 5 \\
\hline December & 2 & 9 & 5 & 5 & 1 & 5 & 5 \\
\hline max $R_{E P}$ & 7 & 10 & 10 & & & & \\
\hline
\end{tabular}

According to the Savage criterion, the minimum level of losses among for the modeled company equals 3 . This value may be taken as the degree of 'problematic character' of this company. In order to determine assessment characteristics of the degree of 'problematic character, we will use the calculation results of the lower and upper limits of the admissible level of economic protectability under conditions of active business conflicts and the uncertainty on the modeled economic entity with the application of the Wald and Hurwitz criteria that satisfy the section $[6 ; 8]$.

While developing the business social responsibility system, the degree of 'problematic character' of the company must be lower than the lower limit of the admissible level of economic protectability. In our case, with regards to the example of the modeled company, this condition is fulfilled, that is $3<6$ (with deviation of 3 units). Otherwise, the method of calculation of the degree of 'problematic character' of the economic entity should be considered faulty. A particular value in this situation is acquired by the quality of drawing the very scale of deviation of the degree of 'problematic character' from the lower admissible level of economic protectability and making a decision regarding the determination of characteristics of the 'problematic character' degree category.

We will take the section of $0 \%$ to $100 \%$ for the deviation interval range and divide it into four equal sectors: $0 \%$ to $25 \% ; 25 \%$ to $50 \% ; 50 \%$ to $75 \% ; 75 \%$ to $100 \%$. Each sector will count for a certain value of deviation from the section $[0 ; 6]$ and will characterize a category of the company's 'problematic character' degree (Tab. 5). 
Tab. 5 - A scale of deviations of the degree of a company's 'problematic character' from the lower limit of the permitted level of economic protectability. Source: (Khoma, 2010)

\begin{tabular}{|l|l|l|}
\hline $\begin{array}{l}\text { Deviation } \\
\text { area }\end{array}$ & $\begin{array}{l}\text { Absolute value of } \\
\text { deviations, } \Delta_{i}\end{array}$ & $\begin{array}{l}\text { Category of the company's 'problematic character' } \\
\text { degree }\end{array}$ \\
\hline I & $0 \leq \Delta_{i} \leq 1.5$ & High degree of 'problematic character' \\
\hline II & $1.5 \leq \Delta_{i} \leq 3$ & $\begin{array}{l}\text { Medium degree of 'problematic character' with in- } \\
\text { creased risk of losses }\end{array}$ \\
\hline III & $3 \leq \Delta_{i} \leq 4.5$ & $\begin{array}{l}\text { Medium degree of 'problematic character' with admis- } \\
\text { sible risk of losses }\end{array}$ \\
\hline IV & $4.5 \leq \Delta_{i} \leq 6$ & Low degree of 'problematic character' \\
\hline
\end{tabular}

In our case, the company with a chaotic fluctuation of the level of economic protectability under the influence of various business conflicts, during three years of its operation with the minimum level of losses of 3 conventional units (see Tab. 4), has an average level of 'problematic character' with an increased risk of losses, including deviations from the value of the lower admissible limit of the company's economic protectability level of 6 points: $\Delta_{i}=6-3=3$ (see Tab. 5). This means that the situation is better with a higher absolute value of deviations in the degree of the company's 'problematic character' from the diagnosed level of economic protectability. This means that, in this case, the decrease in the current level of losses under conditions of active conflict situations is fixed. However, in the case of a high or medium level of the company's 'problematic character' with an increased risk of losses, it is necessary to look for efficient anti-crisis measures regarding the adjustment of the primary functions of the managing economic entity for its sustainable development in a business social responsibility forming system.

\section{CONCLUSION}

Most business conflicts are generated in a business environment by the occurrence of an unfavorable event and uncertainty that destabilizes the integrity of the business social responsibility forming system. The development of a methodology for timely diagnostics of conflict situations on the basis of the classification introduced related to identification of business conflict signs and forecasting them for the future enables making the competitiveness of enterprises and their economic development more predictable and stable, simultaneously protecting the society from various economic issues.

The data on fluctuations of lower and upper limits of admissible levels of a company's economic protectability allow establishing an interconnection with the degree of 'problematic character' of this economic entity. The degree of interconnection depends on the efficiency of the selected method of determination of the degree of 'problematic character' on the basis of the built matrix of losses according to the Savage criterion and the diagnosed level of the company's economic protectability according to the method of structural and functional diagnostics. On the basis of the defined category of the degree of the company's 'problematic character' according to the point scale of deviations, the most efficient management strategy may be chosen. However, after improving the scale with the justification of every step in a deviation change, it is possible to 
study its dynamic development, discovering weak points of financial and economic activity and the deterioration of competitiveness.

\section{References}

1. Adelkin, F. (2005). Results of the study of social responsibility of Ukrainian business. Kyiv: Blakit.

2. Alieksieiev, I., \& Khoma, I. (2017). Transformation of Strategic Management of the Enterprise at the Bifurcation Point in Terms of the Emergence of Business Conflicts. DEStech Transactions on Engineering and Technology Research, (Imeia). https://doi.org/10.12783/dtetr/imeia2016/9321

3. Bazarov, G. Z., Belyaev, S. G., Belykh, L. P. \& Koshkin, V. I. (1996). Theory and practice of crisis management. Moscow: Law and Right, YUNITI.

4. Bielikov, O. (2013). Conflicts in entrepreneurial activity and the possibility of settling them. Retrieved October 10, 2013, from http://justinian.com.ua/article.php?id=2664.

5. Bobryshev, A. D. (2012). Identification of problematic fields in the organization of companies' activity under the influence of the crisis. Problems of forecasting, 4, 127-136.

6. Boin, A., \& Lagadec, P. (2000). Preparing for the Future: Critical Challenges in Crisis Management. Journal of Contingencies and Crisis Management, 8(4), 185-191. https://doi. org/10.1111/1468-5973.00138

7. Chernyavskiy, A. D. (2005). The crisis management by firm. Kyiv: Foreign Trade.

8. Donets, L. I. (2006). Economic risks and methods of their measurement. Kyiv.: Center for Educational Literature.

9. Kapitonenko, M. G. (2009). International conflicts. Kyiv: Lybid. https://doi.org/10.12783/ dtetr/imeia2016/9321

10. Khoma, I. B. (2010). Management of a problem enterprise on the basis of the diagnosed level of economic security. Economics of Development, 4 (56), 91-95.

11. Khoma, I. B. (2012). Formation and use of diagnostics systems of economic protectability of an industrial enterprise: [monograph]. Lviv: Publishing house of Lviv Polytechnic National University.

12. Khoma, I. B. (2014). Formation of the essence of the impact of business conflicts on the state of economic protectability of the enterprise. "Economic Sciences" - The scientific herald of the Kherson State University, 6 (3), 215-218.

13. Khoma, I. B. (2015, March). Management of innovative processes of diagnostics of economic protectability of the enterprise under the influence of business conflicts. Paper presented at meeting of "Modern problems of enterprise management: theory and practice", Kharkiv.

14. Khoma, I. B. (2017, April). Express control of the need of the introduction of subsystem activities for crisis management of enterprise. Paper presented at meeting of "Accounting and analytical support of enterprise management system", Lviv.

15. Konysheva, L. K., Nazarov, D. M. (2011). Fundamentals of the theory of fuzzy sets. St. Petersburg: Peter. https://doi.org/10.1088/1742-6596/1015/3/032026

16. Kuleshova, L. V. (2013). Corporate social responsibility as an instrument for sustainable development of enterprises. Herald of the Donbas state macbine-building academy, 1 (30), 195-199. 
17. Lerbinger, O. (2012). The Crisis Manager: Facing Disasters, Conflicts and Failures. 2nd ed. Hoboken. NJ: Taylor and Francis.

18. Moroz, L. \& Khoma, I. (2017). Economic-Mathematical And Socio-Psychological Aspects Of Management Of The Conflict Situations In The Companies. GIS AP: Economics, Jurisprudence and Management, (12). https://doi.org/10.18007/gisap:ejm.v0i12.1616

19. Osovska, G. V. (2003). Communication in management. Kyiv: Condor.

20. Pauchant, T. C., Mitroff, I. I., \& Lagadec, P. (1991). Toward a systemic crisis management strategy: Learning from the best examples in the US, Canada and France. Industrial Crisis Quarterly, 5(3), 209-232. https://doi.org/10.1177/108602669100500303

21. Pearson, C. M., \& Clair, J. A. (1998). Reframing Crisis Management. The Academy of Management Review, 23(1), 59-76. https://doi.org/10.2307/259099

22. Porter, M. (2017). International competition. Competitive advantages of countries. Publishing house: Alpina Publisher.

23. Pryimak, V. M. (2008). Adoption of managerial decisions. Kyiv: Atika.

24. Rayevnyeva, O. V. (2012). The sanational strategy of industrial enterprise: the mechanism of formation and the models of implementation. Kharkiv: Publishing house «INZHEK».

25. Saienko, Y. (2002). Social responsibility of business in Ukraine. Kyiv: Batiskaph.

26. Starodubska, M. (2005). Social responsibility of business in Ukraine. Kyiv: Ukrainian Independent Center for Political Studies.

27. Tereschenko, O. O. (2004). The crisis financial management in the enterprise. Kyiv: Publishing house of the KNEU.

28. Vasilenko, V. A. (2001). The strategic crisis management and the foundations of sustainability of a company. Culture of people of the Black Sea Region, 16, 165-171.

29. Yurchenko, S. M. (2007). Methods of solving business conflicts of competing enterprises. Retrieved January 21, 2009, from http://rusnauka.com./14.NTP_2007/Economics/21411.doc.htp.

\section{Contact information}

Prof. Iryna Khoma, Doctor of the Sciences

Lviv Polytechnic National University, Ukraine

Institute of Economics and Management, Department of Finance

Ukraine

E-mail:Iryna.B.Khoma@וpnu.ua

ORCID https://orsid.org/0000-0002-3737-1601

Ass. Prof. Liudmyla Moroz, Ph.D.

Lviv Polytechnic National University, Ukraine

Institute of Economics and Management, Department of Management Personnel and Administration

Ukraine

E-mail:Liudmyla.I.Moroz@lpnu.ua

ORCID https://orsid.org/0000-0001-5806-0426 
Ass. Prof. Pavlo Horyslavets, Ph.D.

Lviv Polytechnic National University, Ukraine

Institute of Economics and Management, Department of Finance,

Ukraine

E-mail:Pavlo.A.Horyslavets@Ipnu.ua

ORCID https://orsid.org/0000-0002-1882-2104 